\title{
„Absolutely" modifying adjectives in British and Bulgarian newspapers in comparison with the British national corpus
}

\author{
Irina Stoyanova-Georgieva*
}

\begin{abstract}
The paper studies the collocations formed by 'absolutely' used as an adverbial intensifier for modifying adjectives in a corpus of Letters to the Editor, published in British and Bulgarian newspapers, and the BNC. The results of the study show the similarities between the collocations of 'absolutely' in English and Bulgarian as well as the resemblances in the choice of a syntactic position of the modified adjectives in both languages.
\end{abstract}

Key words: absolutely, collocation, BNC, Bulgarian and British newspapers

\section{Introduction}

According to the Cambridge Advanced Learner's Dictionary absolutely is an adverb meaning completely; "used for adding force to a strong adjective which is not usually used with 'very', or to a verb expressing strong emotion", "a strong way of saying "no"' (see CALD 2008). The reason of absolutely not collocating with certain adjectives is grammatically described as being the "mismatch of the modes of construal of the adjective and the modifier" (see Paradis 1997).

According to The Dictionary of Bulgarian Language of the Institute for Bulgarian Language (see http://ibl.bas.bg/rbe/lang/en/абсолютно) абсолютно is an adverb meaning “напълно, съвършено, безусловно, сьвсем” ('completely, totally, unconditionally, quite' - trans. author's)

From a morphological point of view absolutely is an intensifier**, which belongs to the subgroup of maximizers, an element 'which can denote the upper extreme of the scale' (see Quirk et al. 1985: 445-6, 589). Paradis also places it among maximizers (see Paradis 1997: 28) but she also qualifies them as a subgroup of

\footnotetext{
* PhD student in the Department of English Studies, University of Shumen, Shumen, Bulgaria ** Intensifiers, modifying adjectives, degree words, etc. are widely used and have been the object of studies for many years. They have been given a variety of names. Stoffel divides adverbs into intensifying and downtoning (see Stoffel 1901). Quirk et al call them modifiers (see Quirk et al 1985: 445). Allerton has named them intensifiers despite the somewhat double nature of this concept, implying reinforcement and at the same time including lexemes with an attenuating character (see Allerton 1987: 18). Halliday refers to them by generally calling them submodifers although he mentions the term qualifier intensifiers as well (see Halliday 2004: 356). Paradis (1997: 15) uses the term degree modifier.
} 
totality modifiers, thus allowing absolutely to combine with limit adjectives, too.

Though absolutely is among the most common qualifying adverbs used to modify adjectives in English, and consequently the subject of extensive studies covering its basic characteristics, collocation capacities, recycling, degree modification, etc. (see Stoffel 1901; Benzinger 1971; Quirk et al. 1985; Allerton 1987; Paradis 1997; Paradis 2001; Tagliamonte 2008, etc.) it has not been so far the subject of any comparative studies aiming at collocations of the degree word with adjectives, in our case in English and Bulgarian. Thus, a corpus containing examples in Bulgarian can be examined and tested for similarities in English.

\section{Nature of adjectives}

Linguists adopt various criteria in their attempts to describe the nature of adjectives. Quirk et al. consider them from the point of view of typicality, discussing four different criteria (1985: 403) but also stating that "most adjectives are gradable. Gradability is manifested through comparison" and "through modification by intensifiers" (1985: 435); Collins divides them into qualitative (considered gradable) and classifying (non-gradable) (1990: 65); Paradis also divides adjectives into two groups: gradable and nongradable (1997: 48-49), but also considers that the first group consists of three subgroups: scalar, extreme and limit adjectives. Each subgroup is bounded with a definite type of adverbial modifier: scalar adjectives selecting scalar modifiers; extreme adjectives preferring maximizers, and limit adjectives collocating with totality modifiers (see Paradis 1997: 65).

The class of adjectives in Bulgarian is also closely examined by scholars and they are systematized in two sets. Pashov (2005: 81-82) and Tilkov et al. (1983: 397-399) divide adjectives into: qualitative (качествени) and relative (относителни). Qualitative adjectives are items denoting qualities, intrinsic to nouns. The quality can vary in its intensity so these adjectives are considered gradable. With relative adjectives, on the contrary, the quality is not intrinsic to the noun but is acquired due to its relations with other nouns. Such adjectives do not have the semantic feature gradability. Pashov determines another case related to the modification of relative adjectives into qualitative due to their figurative use: златен часовник - златни ръие. Such modification unlocks the semantic component gradability by turning the relative adjective into qualitative.

Thus the object of our study will be the adverbial intensifier absolutely modifying gradable adjectives.

According to Leech and Svartvik (1994: 172-174) and Quirk et al. (1985: 399) most adjectives can be both attributive (acting as premodifiers of nouns) and predicative (acting as complements of verbs). Though most adjectives can take 
both positions some are restricted to attributive position. Predicative adjectives occur after linking verbs or as object complement. Many of the adjectives used predominantly in predicative position can appear in an attributive one, too, but with a change of meaning. An adjective can also be a postmodifier.

Some linguists present a thorough classification of syntactic positions of single English adjectives; however, they do not elaborate on the types of syntactic positions that are more common with adjectives modified by intensifiers.

According to Pashov (see 2005 81-82) Bulgarian adjectives can perform two syntactic roles: that of attributive adjective (сьгласувано определение), which can lead to a change in their gender and number in order to conform to the rules of concord with the nouns they modify; and that of predicative adjective (сказуемно определение) which can modify nouns in the role of subject or object of a sentence and do not take articles.

Due to natural differences between English and Bulgarian, based on their origin, cultural and historical development, the abovementioned lack of great similarities between the extensive characteristics of Bulgarian and English adjectives and absence of any significant theory dividing Bulgarian degree words into groups, resembling the ones existing for the English language, our first hypothesis is that the examples which will be found in the BNC and the British section of our corpus will not be similar to those found in the Bulgarian section of the corpus. Then we hypothesize that there will be just one or two isolated cases of translation equivalents, and the syntactic positions of the majority of adjectives, modified by the adverb absolutely, will be different in the two languages.

\section{Method of analysis}

The present study is conducted on a comparative basis, its whole corpus consisting of 4521 Letters to the Editor as follows: 3721 articles from the newspaper section of the British National Corpus (BNC) and another 800 Letters to the Editor from 400 British and 400 Bulgarian newspapers (Corpus of Letters to the Editor, hence COLE), collected on a random basis. The media chosen for this study are: The Financial Times, The Independent, The Guardian, The Daily Express, 24 Chasa, Dnevnik, Duma and Lichna Drama. The central idea is to find the similarities and differences between English and Bulgarian in the use of absolutely in its function to modify adjectives. The study benefits from the opportunities offered by a renowned corpus, and tests the samples of a smaller corpus compiled by the author.

Though the corpora do not contain the same type of articles, as COLE consists entirely of Letters to the Editor, while the analysed section of BNC has samples of all kinds of newspaper articles, including letters to the editor, we do not consider this an obstacle as all the articles are classified as newspaper material. 
Taking into consideration the advantages and the limitations provided by the BNC, we applied the following strategy: we searched for the combination of absolutely with any adjective in the newspaper section of the BNC. Then the corpus compiled by the author (COLE) was studied through the use of TextStat, a simple programme for analysis of texts, which produces word frequency lists and concordances.

\section{Analysis of Absolutely in Newspapers}

Though limited, the BNC still outnumbered COLE which provided us with a chance to examine the problem in a wider context.

As a result, the newspaper section of the BNC provided 313 samples of 134 collocations of absolutely, the collocations of absolutely represent $0.003 \%$ from the texts. The most common among them is the combination absolutely delighted which is repeated 23 times, followed by absolutely clear (13 times), and absolutely necessary (13 times). Unfortunately, after a close inspection of the results several of the examples turned out to be inappropriate for the survey as they belonged to an autocue script or contained other inconsistencies. Therefore, the final calculation contains 260 samples of 119 collocations with $0.0025 \%$ of the text consisting of intensifiers. The new calculation showed that the most common among them is still absolutely delighted (23 times), followed by absolutely clear (12 times), absolutely necessary (12 times) and absolutely brilliant, which was mentioned 11 times in its full form and once in short brill.

Compared to the BNC, the British section of COLE contains fewer words and fewer collocations of absolutely modifying an adjective. COLE has only three collocations: absolutely right, absolutely correct, and absolutely set, which make $0.0048 \%$ out of all of its words.

Although the Bulgarian section of COLE is smaller than the BNC, it still provides an opportunity for examination. It has 19 examples of 18 different collocations, $0.0083 \%$ of all the words from the corpus. Because of the small number there is just one repetition: абсолютно вярно (absolutely right) and another partial repetition of the conjunction of absolutely with the lemma and a form of the lexeme: абсолютно неадекватен/неадекватно (absolutely inadequate).

Comparing the initial results, we should state that though the list of collocations is not long it presents an interesting opportunity to check for similarities in the collocations in both languages.

Taking into consideration Quirk et al.'s and Allerton's and Paradis' model we assume that absolutely should collocate with extreme and limit adjectives. Last but not least, it will not occur in combination with scalar and non-gradable adjectives, unless there is a case of contextual modulation. The abovementioned restrictions are due to the nature of the degree word and the category of boundedness. 
English adjectives in the corpus are divided into categories following Allerton's classification for gradable adjectives (see Allerton 1987) and Paradis' criteria (see Paradis 1997: 50):

\begin{tabular}{|lllc|}
\hline Defining features & Scalar adjectives & Extreme adjectives & Limit adjectives \\
\hline Comparison & yes & yes $/$ no & no \\
'How x is it?' & yes & no & no \\
'How x!' & yes & yes & no \\
Oppositeness & antonymy & antonymy & complementarity \\
\hline
\end{tabular}

\section{Analysis \& Discussion}

Comparing the results from the initial analysis, we noticed that absolutely right exists in COLE as well as in BNC, and there are several collocations: 4 in BNC, and 1 in COLE, that have counterparts in the Bulgarian COLE.

(BNC) absolutely necessary - абсолютно необходимо (BULCOLE)

(BNC) absolutely wrong - абсолютно сбъркано (BULCOLE)

(BNC) absolutely unacceptable - абсолютно неприемливо (BULCOLE)

(BNC) absolutely mindless - абсолютно безмозъчни (BULCOLE)

(BRCOLE) absolutely correct - абсолютно вярно (BULCOLE)

In order to be able to analyze them more fully, we applied Allerton's model (1987) for classification of adjectives and Paradis' criteria used to determine gradability in adjectives (see Paradis 1997: 50). Our results are marked in bold.

\begin{tabular}{|lllc|}
\hline Defining features-necessary & Scalar adj. & Extreme adj. & Limit adj. \\
\hline Comparison & yes & yes $/$ no & no \\
'How x is it?' & yes & no & no \\
'How x!' & yes & yes & no \\
Oppositeness & antonymy & antonym & complementarity \\
\hline & & & Limit adj. \\
\hline Defining features-wrong & Scalar adj. & Extreme adj. & no \\
\hline Comparison & yes & yes/no & no \\
'How x is it?' & yes & no & no \\
'How x!' & yes & yes & complementarity \\
Oppositeness & antonymy & antonymy & \\
\hline
\end{tabular}




\begin{tabular}{|lllc|}
\hline Defining features-unacceptable & Scalar adj. & Extreme adj. & Limit adj. \\
\hline Comparison & yes & yes $/$ no & no \\
'How x is it?' & yes & no & no \\
'How x!' & yes & yes & no \\
Oppositeness & antonymy & antonym & complementarity \\
\hline
\end{tabular}

\begin{tabular}{|lllc|}
\hline Defining features-mindless & Scalar adj. & Extreme adj. & Limit adj. \\
\hline Comparison & yes & yes/no & no \\
'How x is it?' & yes & no & no \\
'How x!' & yes & yes & no \\
Oppositeness & antonymy & antonymy & complementarity \\
\hline
\end{tabular}

\begin{tabular}{|lllc|}
\hline Defining features-correct & Scalar adj. & Extreme adj. & Limit adj. \\
\hline Comparison & yes & yes/no & no \\
'How x is it?' & yes & no & no \\
'How x!' & yes & yes & no \\
Oppositeness & antonymy & antonymy & complementarity \\
\hline
\end{tabular}

Based on the model it was found out that all adjectives following absolutely are part of the subclass of extreme or limit adjectives which corresponds to what was derived from Paradis' and Allerton's models.

In order to test the corpuses for translation equivalents among the collocations with counterparts in the Bulgarian section of COLE we resort to using the WordNet and the BulNet.

The first collocation of absolutely is with the adjective necessary. Thus we take into consideration the definition of necessary according to WordNet: absolutely essential, unavoidably determined by prior circumstances; antonym - unпесеssary. BulNet characterizes необходимо as:

чието присъствие, навременност или наличност са важни или задължителни за постигането на даден резултат или са наложени от някого или нещо; съществена, основна нужда, която е задължителна с оглед на ситуацията или обстоятелствата (whose presence, timeliness or availability are important or obligatory for the achievement of a certain result or are imposed by somebody or something; essential, basic need, which is obligatory as regards the situation or the circumstances - trans. author's).

The given definition is nearly the same as the one provided by WordNet; 
however, more detailed.

The second collocation is absolutely wrong, where WordNet provides the following information: incorrect, not correct; not in conformity with fact or truth; contrary to conscience or morality or law; improper. Unfortunately, the lack of data about сбъркано in the BulNet does not give us the opportunity to discuss the case and decide whether the two collocations are exact translation equivalents.

As regards unacceptable, it is presented as: not adequate to give satisfaction; not acceptable; not welcome; impossible; not conforming to standard usage. Its antonyms are: satisfactory, acceptable, tolerable, standard. Неприемливо is defined in absolutely the same way:

който не езадоволителен, не отговаря на очакванията; който не може да се допусне, да се позволи; който не отговаря на определени критерии или не е достатъчно добър за нещо; който според преценката на носителите на езика е граматично правилен, но се отклонява от утвърдената езикова употреба, etc. (which is not satisfactory; does not meet expectations; which is inadmissible; not allowed; which does not meet certain criteria or is not good enough for something; which according to the assessment of native speakers is grammatically correct, but deviates from standard language usage; etc. - trans. author's).

Mindless is described as: "lacking the thinking capacity characteristic of a conscious being; requiring little mental effort; unmindful, forgetful, devoid of intelligence or thought; reasonless, senseless. Its antonyms are meaningful, intellectual, wise, reasonable". Безмозъчен has the same characteristics in Bulgarian: "на когото му липсва интелект или говори или действа, без да мисли (who lacks intellect or who speaks or acts without thinking - trans. author's), and its antonyms are also the same: sensible, intelligent".

WordNet gives the following definition about correct: "right (free from error; especially conforming to fact or truth); socially right or correct; in accord with accepted standards of usage or procedure; correct in opinion or judgment. Its antonyms are: incorrect, wrong, improper". Вярно has absolutely the same definition in Bulgarian: "който е в сьгласие с определени факти или състояние на нещата, не противоречи на истината, не съдържа грешки (who agrees with certain facts or state of things; does not contradict to the truth; does not contain mistakes - trans. author's). Antonym: wrong".

\section{Conclusion}

In conclusion, the findings show that $25 \%$ of the samples in the Bulgarian Corpus of Letters to the Editor have their exact matches in the English corpora. This disproves our initial hypothesis that due to the natural differences between the languages there will be no, or if present, an insignificant number of translation equivalents in the Bulgarian and English sections of our corpus. 
As to our second hypothesis concerning the syntactic position of the adjectives modified by absolutely, it was interesting to find out that all intensified adjectives show definite preference of predicative position. Approximately $86 \%$ of the English adjectives modified by absolutely and $63 \%$ of the Bulgarian ones are in predicative position, despite the fact that there are representatives of all kinds of groups: adjectives used in attributive and predicative position without any change of meaning, such that only appear in predicative position, and several that premodify nouns, it is the predominant use of predicative adjectives that attracts our attention and can be incentive for a future research in order to find out whether this tendency will be preserved in larger corpora.

\section{References:}

Allerton 1987. Allerton D. J. "English Intensifiers and Their Idiosyncrasies". Language Topics Essays in Honour of Michael Halliday. Vol. 2: 15-31. Amsterdam/Philadelphia: John Benjamins Publishing Company, 1987. 6-13.

Benzinger 1971. Benzinger E. M. Intensifiers in Current English, 1971.

Leech, Svartvik 1994. Leech G., J. Svartvik. A Communicative Grammar of English. New York: Longman Group Limited, 1994.

Paradis 1997. Paradis C. Degree Modifiers of Adjectives in Spoken British English. Lund: Lund University Press, 1997.

Quirk et al. 1985. Quirk R., Greenbaum S., Leech G., J. Svartvik. A Comprehensive Grammar of the English Language. Essex: Longman, 1985.

Sinclair 1990. Sinclair J. Collins Cobuild English Grammar. London: Collins, 1990.

Stoffel 1901. Stoffel C. Intensives and Down-toners. A Study in English Adverbs. Forgotten Books, reprinted 2013.

Tagliamonte 2008. Tagliamonte S. A. "So Different and Pretty Cool! Recycling Intensifiers in Toronto, Canada". English Language and Linguistics 12.2: 361-394. Cambridge: Cambridge University Press, 2008.

Walter et al. 2008. Walter E. et al. Cambridge Advanced Learner's Dictionary. Cambridge: Cambridge University Press, 2008.

Pashov 2005. Pasov P. Balgarska gramatika. Plovdiv: Izdatelska kashta "Hermes", 2005.

Tilkov et al. 1983. Tilkov D., Stoyanov S., K. Popov. Gramatika na savremennia balgarski knizhoven ezik. Vol. 2 Morfologia. Sofia: Izdatelstvo na Balgarskata academia na naukite, 1983.

BulNet $<$ http://dcl.bas.bg/bulnet/>.

Princeton University “About WordNet.” WordNet. Princeton University, 2010. <http:// wordnet.princeton.edu>. 